\title{
Green Synthesis and Antibacterial Activity of Gold Nanoparticles of Digera muricata
}

\author{
RIDA SHAH ${ }^{1}$, S. A. SHAH ${ }^{1 *}$, SUMAIRA SHAH ${ }^{2}$, S. FAISAL ${ }^{1}$ AND F. ULLAH ${ }^{3}$ \\ ${ }^{1}$ Department of Biotechnology, ${ }^{2}$ Department of Botany, Bacha Khan University Charsadda, ${ }^{3}$ Centre of Biotechnology and \\ Microbiology, Bacha Khan University, Pakistan
}

\section{Shah et al: : Green Synthesis of Gold Nanoparticles of Digera muricata}

\begin{abstract}
The current research work was about a suitable eco-friendly process to produce gold nanoparticles using ethanol extract of Digera muricata. Completion of synthesis, size and morphology of nanoparticles and various functional groups present were confirmed using various techniques. Formation and physical appearance of gold nanoparticles was confirmed through the presence of dark purple colour. Ultraviolet/ Vis spectra give a sharp narrow peak at the $\lambda \max$ specified for gold nanoparticle. Scanning electron microscopy indicated nanoparticles were spherical in shape, fully dispersed in reaction medium with $40 \pm 5$ $\mathrm{nm}$ size. $X$-ray diffraction analysis revealed that synthesized nanoparticles were crystalline with an average particle size of $33 \mathrm{~nm}$. The presence of bio-organic compound was detected by Fourier-transform infrared spectroscopy. Antibacterial potential of the synthesized gold nanoparticles of Digera muricata extract was evaluated in comparison to crude ethanol extract. The gold nanoparticles exhibited greater antibacterial potential as compared to crude ethanol extract of Digera muricata against different drug-resistant bacteria including Vibrio cholera, Staphylococcus pyrogen, Klebsiella, Citrobacter and Enterobacter. The results indicated that the gold nanoparticles could be used as a promising antibacterial agents
\end{abstract}

Key words: Digera muricata, ethanol extract, gold nanoparticles, characterization, drug resistant bacteria

Nanotechnology, a field of science and technology at molecular level controls and exploits the structure of matter on a large scale below 100 nanometers ${ }^{[1]}$. It is based on its ability of controlling metals into their nano size, which eventually change the physical, chemical and optical properties of metals. This is simply because of the nanoparticles (NPs) greater surface area per weight than larger particles, which make them more reactive as compare to other molecules ${ }^{[2]}$. On the base of size, distribution and morphology, NPs have new or improved properties. Green synthesis of metal NPs is devoid of consuming high energy, pressure and temperature. It is a useful and eco-friendly method to synthesize NPs on a large scale that attracted researchers throughout the world to find out the potential of different herbs. On the other hand, the chemical synthesis of NPs might result in poisonous chemicals adsorbed on their surface which might have unfavorable effects in medical applications ${ }^{[3]}$.

Gold NPs (Au-NPs) have found use in diagnostic and drug delivery areas ${ }^{[4]}$. Au-NPs are synthesized from leaves, bark, stem, roots of herbal plants ${ }^{[5]}$. Au-NPs, also called gold colloids, have attracted

*Address for correspondence

E-mail: sajjadbiotec@gmail.com

March-April 2020 attention for the fabrication of smart sensing due to their exclusive properties in devices in biomedical sciences as diagnostic tools in multi-disciplinary research fields ${ }^{[6]}$. In recent years in vitro approaches have been developed using plant extracts to bio reduce metal ions to synthesize NPs. Digera muricata species belongs to family Amaranthaceae. It is also known as Digera arvensis, Digera alternifolia and false amaranth or Digera angustifolia. All these are the synonyms of D. muricata. It is herbaceous plant grown annually (fig. 1). The whole plant especially its leaves and stems are useful due to their curative effects. It used for the inflammation, urination, as refrigerant and in sexual anomaly ${ }^{[7,8]}$. D. muricata is used in kidney disorder in folk medicine. The whole plant is used for digestive system as well as in urinary disorders. The extract of this plant was used in biliousness ${ }^{[9]}$. A decoction of leaves is given once in a day as kidney stone treatment ${ }^{[10]}$.

This is an open access article distributed under the terms of the Creative Commons Attribution-NonCommercial-ShareAlike 3.0 License, which allows others to remix, tweak, and build upon the work non-commercially, as long as the author is credited and the new creations are licensed under the identical terms

Accepted 24 January 2020

Revised 25 December 2019

Received 09 July 2019

Indian J Pharm Sci 2020;82(2):374-378 


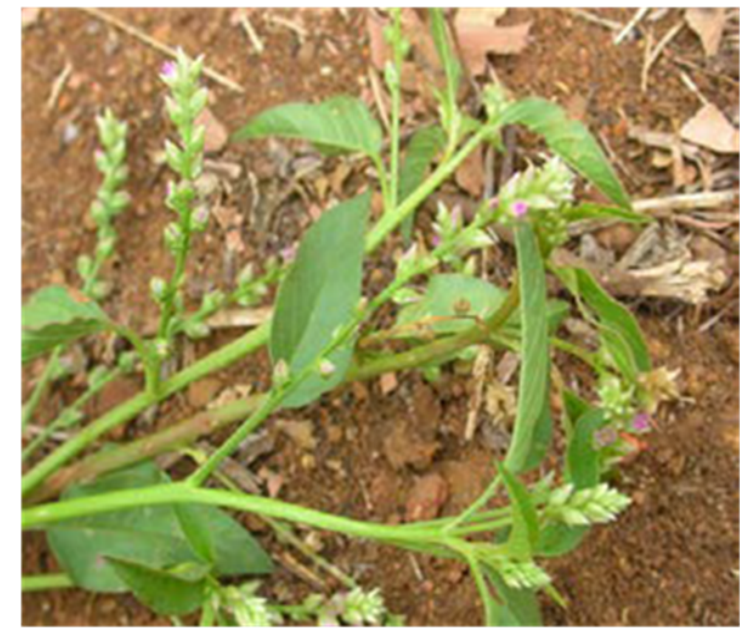

Fig. 1: Digera muricata

Leaf paste is used in prevention of pus formation. The crushed plant is used as a mild astringent in bowel complaints $^{[11]}$. The whole plant extract is also used to improve blood content ${ }^{[12]}$. D. muricata has flavonoids and been used as an anticancer drug ${ }^{[13]}$. Keeping in view of the above literature, the aim of current work is the biosynthesis of Au-NPs and evaluation of antibacterial activity against various drug-resistant bacterial strains. For the synthesis of Au-NPs and antibacterial assay, auric chloride $\left(\mathrm{AuHCl}_{4}\right)$ was purchased from (E. Merck, Darmstadt, Germany), D. muricata extract, ethanol, nanopure water are used throughout the experiment. Bacterial strains used were Enterobacter, Vibrio cholera, Klebsiella pneumonia, Streptococcus pyrogen and Citrobactor. The plant was collected from the local fields of District Charsadda, Pakistan. After collection the plant material was washed 3 times using distilled water to remove all sand and dust particles. The plant was the cut into pieces and shade dried for 10-15 d. The dried plant was powdered in a mechanical grinder to a fine powder. Extract was prepared by soaking $500 \mathrm{~g}$ of powdered plant in $1500 \mathrm{ml}$ of ethanol with shaking on an electric shaker at room temperature for $24 \mathrm{~h}$. The extract was filtered through a Whatman filter paper No. 1 and the filtrate was stored in the refrigerator at $4^{\circ}$ for further studies.

Basically, $0.6 \mathrm{~g}$ semi solid extracts was dissolved in $100 \mathrm{ml}$ distill water for further analysis. The stock solutions of different concentration were prepared and stored at $4^{\circ}$. Seven hundred parts per million of the sample was mixed with $1 \mathrm{mM}$ aqueous solution of $\mathrm{AuHCl}_{4}$ in different ratios by volume. Ten millilitres of plant extract was mixed with $10,20,30,40,50$ and $60 \mathrm{ml}$ of aqueous $\mathrm{AuHCl}_{4}$ solution to make 1:1, 1:2, 1:3, 1:4, 1:5 and 1:6, respectively for synthesising Au-NPs and these mixtures were stirred for $3 \mathrm{~h}$ till the color of solution completely changed to dark purple. To confirm the $\mathrm{Au}$ ion reduction, $\mathrm{UV} / \mathrm{Vis}$ spectra of the prepared solutions were recorded against distilled water while ethanol was used as the blank. At a resolution of $1 \mathrm{~nm}$ (300-800 nm) the spectral analysis was completed on a double beam UV/Vis spectrophotometer (PerkinElmer) set at a resolution of $4 \mathrm{~cm}^{-1}$ in the range of $4000-0 \mathrm{~cm}^{-1}$. $\mathrm{KBr}$ pellets were prepared with these samples and Fourier-transform infrared spectroscopy (FTIR) analysis was completed using a thin $\mathrm{KBr}$ disc compressed using a hydraulic pellet press. FTIR spectra were run at the Chemistry Department, Bacha Khan University Charsadda, Pakistan. X-ray diffraction (XRD) was used for detection of crystalline nature and phase purity of the synthesized Au-NPs. XRD was set at a current of $30 \mathrm{~mA}$ with $\mathrm{CuK} \alpha 1$ radiation and a voltage of $40 \mathrm{kV}$. Morphology, size and electron diffraction pattern of the synthesized Au-NPs were determined using scanning electron microscopy (SEM) at a voltage $15 \mathrm{kV}$, respectively. Streptococcus pyrogen, Klebsiella pneumonia, Enterobacter, Vibrio cholera and Citrobacter were cultured in Luria broth medium as a suspension culture in $250 \mathrm{ml}$ flasks containing $1.25 \mathrm{~g} / 50 \mathrm{ml}$ in a shaker incubator set $150 \mathrm{rpm}$ at $30^{\circ}$ overnight. After reaching best growth all strains were stored at $4^{\circ}$ in an incubator. Bactericidal activity of the plant extract and Au-NPs was carried out on 5 human pathogenic bacteria, Enterobacter, Streptococcus pyrogen, Klebsiella pneumonia, Vibrio cholera and Citrobacter using the agar well diffusion method. Nutrient agar was prepared by dissolving $10 \mathrm{~g} / 500 \mathrm{ml}$ along with $2.5 \mathrm{~g}$ agar. Medium was autoclaved at $121^{\circ}$ for $20 \mathrm{~min}$ and then poured into sterilized Petri dishes, allowed to solidify for $1.5 \mathrm{~h}$ in a laminar flow under UV light. On sterilized agar plates fresh overnight culture of inoculums $(200 \mu 1)$ were spread and wells were made with the help of a stainless steel cork borer. Test solution of each ratio of Au-NPs at a concentration of $50 \mu \mathrm{l} /$ well and the plant extract were added to each well of agar plates along with the control and incubated at $37^{\circ}$ for $24 \mathrm{~h}$. Distilled water used as a positive control. The diameter of the inhibition zone formed around the well were measured and the antibacterial activity was calculated using the standard procedure ${ }^{[14]}$. The extract of D. muricata was used as a reducing agent for the preparation of Au-NPs, which were characterized using various methods. The prepared Au-NPs were analyzed using UV, FT-IR, XRD and SEM. Further the prepared Au-NPs were evaluated for antibacterial activity. After exposure to D. muricata extract reduction of metal ion and the appearance of dark purple color indicated the 
production of Au-NPs. The change in color occurred due to the surface plasmon resonance of metal nanoparticles. Usually reduction of gold ions to Au-NPs a time taking process. After the addition of plant extract rapid color change occurred and the concentration of color was directly proportional to stirring and uniform heat. After continuous stirring $(80 \mathrm{rpm})$ for $3 \mathrm{~h}$ the color deepens to purple indicated the formation of Au-NPs and uniform heat $\left(40^{\circ}\right)$ stopped the particles from aggregation as shown in fig. 2 . Previous studies suggested that the change in color occurred on completion of the reaction. In a previous study, the reaction mixture of $10 \mathrm{ml} \mathrm{AuHCl}_{4}$ and $2 \mathrm{ml}$ of extract had changed color from light yellow to stable violet color on continuous stirring for $10 \mathrm{~min}^{[15]}$. It was also reported that the solution color first changed into brownish pink and with rising incubation time from $30 \mathrm{~min}$ to $48 \mathrm{~h}$ changed to pink. The study also reported that reaction was complete in $48 \mathrm{~h}$ but in the present study the reaction tokk only $3 \mathrm{~h}$ for completion. It could be concluded that due to surface plasmon resonance, which is due to collective oscillation of electrons. It is reported previously that by adding $5 \mathrm{ml}$ plant extract to $3 \mathrm{mM}$ aqueous solution of $\mathrm{AuHCl}_{4}$ and stirring it continuously at room temperature the color of solution gradually changes from light pink to characteristic dark ruby red when the reaction was completed ${ }^{[16]}$. Similarly a reaction mixture of $10 \mathrm{ml} \mathrm{AuHCl}_{4}$ and $2 \mathrm{ml}$ extract changed colour from light yellow to stable violet on continuous stirring for $10 \mathrm{~min}^{[17]}$. The Au-NPs formation was confirmed by UV/Vis spectra analysis. The first clue of Au-NP formation was conversion of pale yellow color into dark purple. Various concentrations of Au-NPs and ethanol extract of the plant were used for optimization. Each ratio gave different absorbance peaks. The maximum absorbance peak was recorded at $1: 1$ at wavelength at $535 \mathrm{~nm}$, which is then followed by $1: 2,1: 3$ and $1: 4$, respectively. At $1: 5$ and 1:6 ratios the

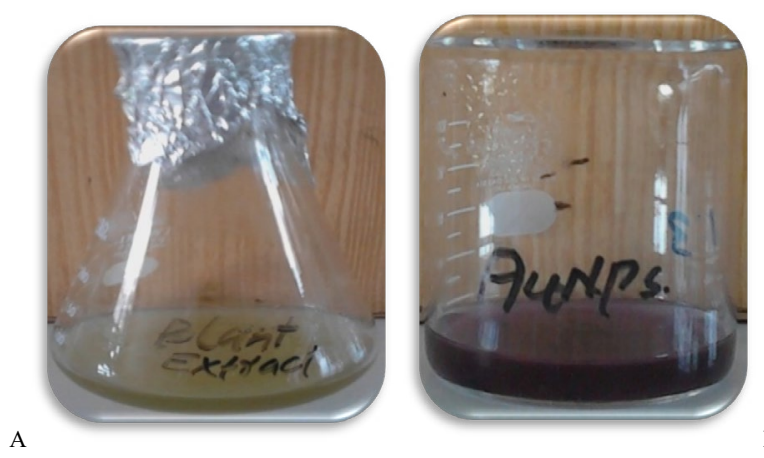

Fig. 2: Photographs of plant crude extract and Au-NPs A. Crude extract of $D$. muricata B. gold nanoparticles (Au-NPs)

March-April 2020

Indian Journal of Pharmaceutical Sciences

376 peak became broader and absorbance decreased with large particle size (fig. 3). Narrow sharp peaks represented that the synthesized NPs were small, spherical in shape and polydisperse with no aggregation. The plasmon band frequency decreased as the size of NPs increased and the band shifted to longer wavelength.

D. muricata extract was accountable for the synthesis of NPs and played a major role in the production. Natural product extracts acted as reducing agent for the generation of metal NPs. Previous finding suggested that the absorbance range for Au-NPs is $500-600 \mathrm{~nm}$. In a reported study on biosynthesis of Au-NPs using Azimat etracantha leave extract showed absorbance band was between $535-550 \mathrm{~nm}^{[18]}$. Similarly Au-NPs were prepared with the help of Azadirachta indica (Neem) leaf extract, which showed absorbance peak at $560 \mathrm{~nm}^{[19]}$. Literature review confirmed that the spectral analysis in the present study was consistent with previous findings. FTIR analysis was used to characterize the NPs and observed chemical changes in the functional groups of D. muricata extract, which interacted with $\mathrm{Au}$ ions as shown in fig. 4. The D. muricata extract exhibited many peaks of absorption, which revealed that the plant has a variety of compounds present in it. Spectra of plant extract and Au-NPs revealed bands, 2922 and 3040, 2856 and 2848, 1730 and 1626,1619 and 1398 and 1376 and $1038 \mathrm{~cm}^{-1}$. The peaks at 1162,1044 , and $816 \mathrm{~cm}^{-1}$ found in the plant extract were absent in the NPs. This indicated that these functional groups interacted with $\mathrm{Au}$ ion and were responsible for reduction of $\mathrm{Au}^{3+}$ to $\mathrm{Au}^{\mathrm{o}}$. The band at 2922 and $2856 \mathrm{~cm}^{-1}$ corresponded to asymmetric stretching of $\mathrm{C}-\mathrm{H}$ groups while at 816 was due to $\mathrm{C}-\mathrm{H}$ bending. The $\mathrm{C}=\mathrm{O}$ stretch present at $1376 \mathrm{~cm}^{-1}$ while C-C stretch present at 1619, 1162 and $1044 \mathrm{~cm}^{-1}$. The band at 1730 represented N-H stretching. The FT-IR spectrum of Au-NPs revealed shift in the C-H groups from 2922 to $3040 \mathrm{~cm}^{-1}$ and from 2856 to $2848 \mathrm{~cm}^{-1}$. $\mathrm{N}-\mathrm{H}$ stretches shifted from 1730 to $1626 \mathrm{~cm}^{-1}$, C-C stretching shifted from 1619 to $1398 \mathrm{~cm}^{-1}, \mathrm{C}=\mathrm{O}$ stretching at 1370 was shifted in Au-NPs to $1038 \mathrm{~cm}^{-1}$. Through XRD analysis the exact nature and size of Au-NPs were studied. The strong and narrow diffraction peaks indicated that the product is crystalline in nature as shown in fig. 5. The XRD analysis showed peaks at $2 \theta=85^{\circ}, 73^{\circ}, 70^{\circ}, 67^{\circ}$ and $55^{\circ}$ can be indexed to the (111), (200), (220) and (311), respectively. The formation of nanoparticles was confirmed by the broad Bragg's peaks. By using simple aqueous reduction method it is possible to obtain monodispersed Au-NPs with controllable size and uniform shape. The mean 
size of Au-NPs was calculated by the Debye-Scherrer's Eqn by determining the width of the (111) Bragg's reflection $^{[20]}$. The XRD peaks were assigned to diffraction from the (111), (200), (220), (311), (222) planes of face centered cubic ( $\mathrm{fcc}$ ) crystal structure. The peak corresponding to (111) was the more intense than the other planes suggesting that (111) was the predominant orientation and the synthesized Au-NPs were crystalline in nature. Similar results were reported previously on Au-NPs synthesis ${ }^{[21]}$. It was impossible to form anisotropic Au-NPs because of the symmetry breaking in fcc metals. Face centered cubic metals have tendency to nucleate and grow into cloned and multiple cloned particles with their surfaces bounded by the lowest-energy (111) facets on the nanometer scale ${ }^{[22]}$. It could be concluded from the SEM images that the size

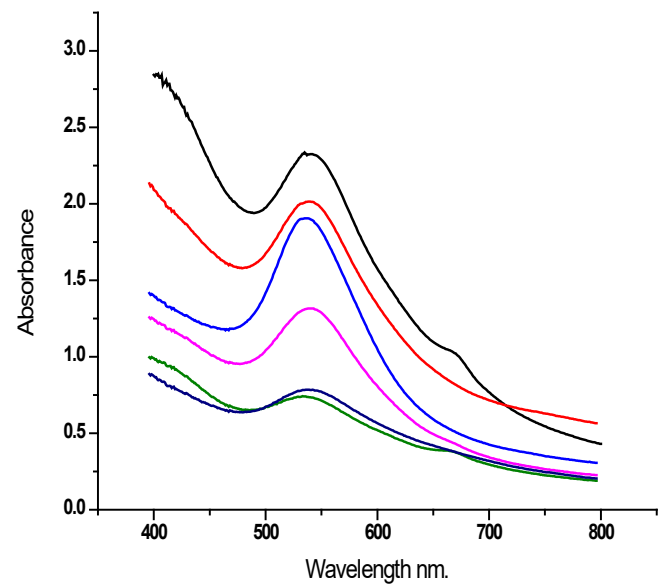

Fig. 3: UV/Vis spectra of Au-NPs from Digera muricate (一) 1:1,(一)1:2,(-)1:3,(-)1:4,(-)1:5,( -) 1:6

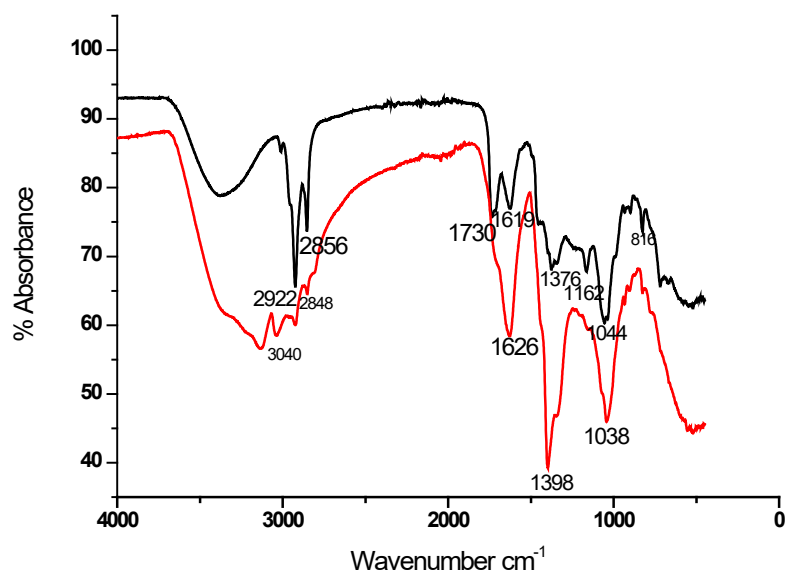

Fig. 4: FTIR spectra of Au-NPs of Digera muricata (一) Extract, (一) Au NPs of the particles is $40-55 \mathrm{~nm}$ using image $\mathrm{j}$ software. The size was not in good agreement with the size as calculated from XRD graph using Debby Sherrers formula. Therefore, it was concluded that there was agglomeration between the nanoparticles as shown in fig. 6. The large grain size is due to the aggregation of particles. The overall morphology of synthesized nanoparticles is spherical in shape. In this study, the antibacterial activity of the plant extract and different ratios of Au-NPs prepared were studied against Enterobacter, Vibrio cholera, Klebsiella pneumonia, Streptococcus pyrogen and Citrobactor. Results obtained showed that ethanol extract of $D$. muricata as well as Au-NPs showed antibacterial activity. The results of antibacterial screening is presented in Tables 1 and 2. The maximum inhibition shown by $1: 1$ ratio against Citrobacter was $15 \mathrm{~mm}$ and 1:3 ratio against C. vibrio was also $15 \mathrm{~mm}$ while minimum inhibition was produced by $1: 5$ ratio against $C$. vibrio $6 \mathrm{~mm}$ and 1:6 against Citrobacter was $5 \mathrm{~mm}$. The plant extract and the Au-NPs showed antibacterial activity against bacterial strains tested at the specified concentrations. A previous study reported antibacterial activity of Au-NPs synthesized with Caesalpinia pulcherrima

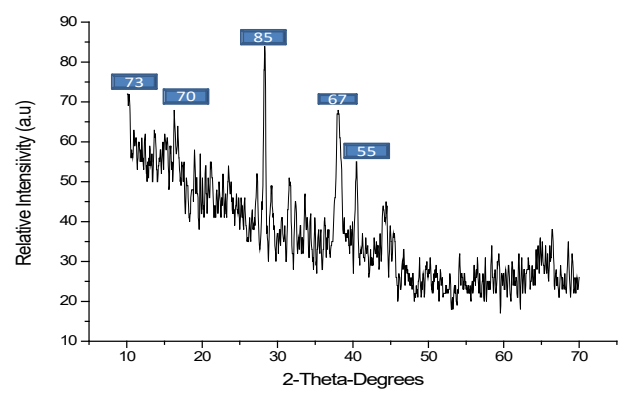

Fig. 5: XRD patterns of Au-NPs of Digera muricata

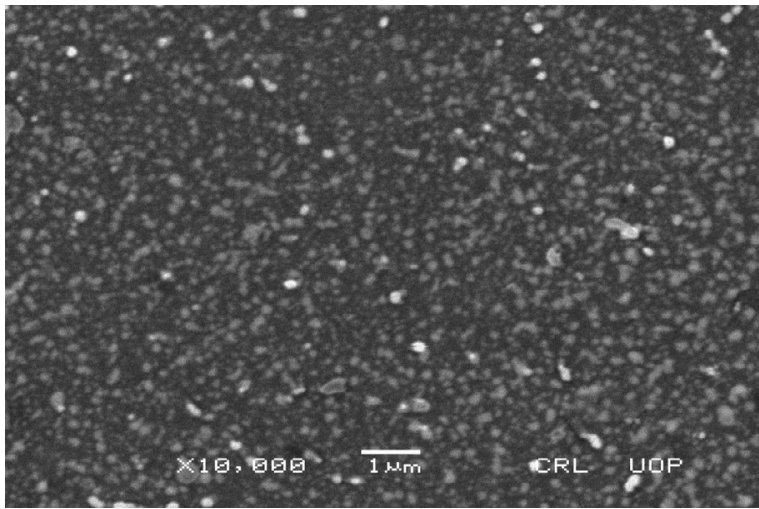

Fig. 6: SEM image of Au-NPs of Digera muricata

TABLE 1: ANTIBACTERIAL EFFECT OF PLANT EXTRACT

\begin{tabular}{lcccccc}
\hline Plant extract & Control & Streptococcus pyrogen & Vibrio cholera & Klebsiella & Enterobacter & Citrobacter \\
\hline $50 \mu \mathrm{l}$ & 0.0 & 10 & 11 & 9 & 12 & 7 \\
\hline
\end{tabular}

Diameter of zone of inhibition in $\mathrm{mm}$ 
TABLE 2: ZONES INHIBITION PRODUCED BY DIFFERENT RATIOS OF AU-NPS

\begin{tabular}{|c|c|c|c|c|c|}
\hline \multicolumn{6}{|c|}{ Zones of inhibition $(\mathrm{mm})$} \\
\hline Test samples & Streptococcus pyrogen & Vibrio cholera & Klebsiella & Enterobacter & Citrobacter \\
\hline $1: 1$ & 13 & 13 & 13 & 14 & 15 \\
\hline $1: 2$ & 10 & 11 & 12 & 13 & 13 \\
\hline $1: 3$ & 11 & 15 & 9 & 13 & 10 \\
\hline $1: 4$ & 12 & 12 & 11 & 12 & 10 \\
\hline $1: 5$ & 7 & 6 & 10 & 8 & 7 \\
\hline $1: 6$ & 10 & 8 & 7 & 9 & 5 \\
\hline Control & _ & _ & _ & _ & _ \\
\hline
\end{tabular}

Concentration used was $50 \mu \mathrm{l} /$ well

extracts $^{[23]}$. The Au-NPs found to be more effective against human pathogenic bacteria species as compared to the crude extract. These Au-NPsappear to have the potential to be used against bacterial infections.

\section{Conflict of interest:}

Authors declared that there is no conflict of interest.

\section{REFERENCES}

1. Rathjen D, Read L. Nanotechnology. Enabling technologies for Australian innovative industries. Paper prepared by an independent working group for the Prime Minister's Science, Engineering and Innovation Council, PMSEIC. 2005.

2. Veerapandian M, Yun K. Functionalization of biomolecules on nanoparticles: specialized for antibacterial applications. Appl Microbiol Biotechnol 2011;90(5):1655-67.

3. Rao ML, Savithramma N. Biological synthesis of silver nanoparticles using Svensonia hyderabadensis leaf extract and evaluation of their antimicrobial efficacy.Int J Pharm Sci Rev Res 2011;3(3):1117.

4. Song JY, Jang HK, Kim BS. Biological synthesis of gold nanoparticles using Magnolia kobus and Diopyros kaki leaf extracts. Process Biochem 2009;44(10):1133-8.

5. Daniel MC, Astruc D. Gold nanoparticles: assembly, supramolecular chemistry, quantum-size-related properties, and applications toward biology, catalysis, and nanotechnology. Chem Reviews 2004;104(1):293-346.

6. Ahmed KBA, Subramanian S, Sivasubramanian A, Veerappan G, Veerappan A.Preparation of gold nanoparticles using Salicornia brachiata plant extract and evaluation of catalytic and antibacterial activity.Spectrochim Acta A Mol Biomol Spectrosc 2014;130:54-8.

7. Sheth AK, Mitaliya K, Joshi S. The herbs of Ayurveda. Vol-1. Published, Edited and distributed by Ashok Sheth. 2005.

8. Kirtikar KR, Basu BD. Indian medicinal plants. 2nd ed. BioGreen Books; 1918.

9. Sharma N, Vijayvergia R. A Review on Digera muricata (L.) Mart-a great versatile medicinal plant. Int J Pharm Sci Rev Res 2013;20(1):114-9.

10. Hariharan A, Begum TN, Ilyas MH, Jahangir HS, Kumpati P, Mathew S, et al. Synthesis of plant mediated gold nanoparticles using Azima tetracantha Lam. leaves extract and evaluation of their antimicrobial activities. Pharmacog J 2016;(8):5.

11. Rahman MA, Begum K, Rashid ME, Harun-ur-Rashid M. Medicinal plant diversity in the flora of Bangladesh and their conser. Plant Archives 2012;12(2):1023-35.

12. Shah A, Marwat SK, Gohar F, Khan A, Bhatti KH, Amin M, et al. Ethnobotanical study of medicinal plants of semi-tribal area of Makerwal \& Gulla Khel (lying between Khyber Pakhtunkhwa and Punjab Provinces), Pakistan. Am J Plant Sci 2013;4(1):98.

13. Usmani S, Arshad H, Farooqui AHA, Mohammed A, Sahabjada S, Mohammed A, et al. Anti-proliferative Activity of Crude Extract and Fractions Obtained from Digera muricata on HeLa Cell Lines of Human Cervix and A549 Cell Lines of Human Lung. Pharmacog J 2014;(6): 32-8.

14. Jayaseelan C, Rahuman AA, Kirthi AV, Marimuthu S, Santhoshkumar T, Bagavan A, et al. Novel microbial route to synthesize $\mathrm{ZnO}$ nanoparticles using Aeromonas hydrophila and their activity against pathogenic bacteria and fungi. Spectrochim. Acta A: Mol. Biomol. Spectrosc 2012;90:78-84.

15. Dorosti N, Jamshidi F. Plant-mediated gold nanoparticles by Dracocephalum kotschyi as anticholinesterase agent: Synthesis, characterization, and evaluation of anticancer and antibacterial activity. $J$ Appl Biomed 2016;14(3):235-45.

16. Rajeshkumar S, Malarkodi C, Gnanajobitha G, Paulkumar K, Vanaja M, Kannan C, et al. Seaweed-mediated synthesis of gold nanoparticles using Turbinaria conoides and its characterization. J Nanostructure Chem 2013;3(1):44.

17. Dorosti N, Jamshidi F. Plant-mediated gold nanoparticles by Dracocephalum kotschyi as anticholinesterase agent: synthesis, characterization, and evaluation of anticancer and antibacterial activity. J Appl Biomed 2016; 14(3):235-45.

18. Hariharan A, Begum TN, Ilyas MH, Jahangir HS, Kumpati P, Mathew S, Govindaraju A, Qadri I.Synthesis of plant mediated gold nanoparticles using Azima tetracantha Lam. leaves extract and evaluation of their antimicrobial activities. Pharmacog J 2016;8(5).

19. Shankar SS, Rai A, Ahmad A, Sastry M. Rapid synthesis of $\mathrm{Au}, \mathrm{Ag}$, and bimetallic $\mathrm{Au}$ core-Ag shell nanoparticles using Neem (Azadirachta indica) leaf broth. Colloid Interfac Sci 2004;275(2):496-502.

20. Borchert H, Shevchenko EV, Robert A, Mekis I, Kornowski A, Grübel G, et al.Determination of nanocrystal sizes: a comparison of TEM, SAXS, and XRD studies of highly monodisperse CoPt3 particles. Langmuir 2005;21(5):1931-6.

21. Aromal SA, Philip D. Benincasa hispida seed mediated green synthesis of gold nanoparticles and its optical nonlinearity. Physica E Low Dimens Syst Nanostruct 2012;44(7-8):132934.

22. Goubet N, Portalès H, Yan C, Arfaoui I, Albouy PA, Mermet A, et al. Simultaneous growths of gold colloidal crystals. J Am Chem Soc 2012;134(8):3714-3719.

23. Nagaraj B, Divya TK, Malakar B. Phytosynthesis of gold nanoparticles using Caesalpinia pulcherrima (peacock flower) flower extract and evaluation of their antimicrobial activities. Dig J Nanomater Bios 2012;7(3):899-905. 